


\section{Niños e infancia en la narrativa de Amparo Dávila}

\section{Children and Childhood in Amparo Dávila's Narrative}

Jorge Antonio Muñoz Figueroa Universidad Nacional Autónoma de México, México jmf.cepe@gmail.com

Resumen: El propósito de este texto es analizar las representaciones de la infancia en los cuentos de Amparo Dávila (1928-2020). Si bien es cierto que los menores de edad no figuran como protagonistas en la obra de Dávila, en un buen número de relatos se presentan constantes que remiten a lugares comunes sobre la niñez, por ejemplo la inocencia o la felicidad que la caracterizan. No obstante, tales nociones son puestas en duda en la prosa daviliana, tal como ocurre en las narraciones de otros creadores contemporáneos; en una visión de conjunto, constatamos que los escritores de la llamada Generación de medio siglo erosionan la idea de la infancia como una época maravillosa, antes bien, se dan a la tarea de caracterizarla, en numerosos ejemplos, como una etapa de soledad, a veces de abandono. Dentro de las reformulaciones que goza el tema de la infancia a partir de la década de 1950, las aportaciones de la talentosa escritora zacatecana nos alejan de las típicas imágenes de la niñez y nos permiten postular interpretaciones que revelan que los "reyes del hogar" no siempre traen dicha ni disfrutan plenamente la alegría de los primeros años de su vida. 
Palabras clave: Amparo Dávila, narrativa mexicana, infancia, inocencia, soledad.

Abstract: This paper analyses how childhood is represented in Amparo Dávila's (1928-2020) short stories. While it is true that infants are not protagonists in Dávila's work, it is also necessary to mention that many of her stories show ideas that refer clichés about the childhood, such as its characteristic innocence and happiness. However, such notions are questioned in Dávila’s prose as well as in some other contemporary writers' narratives. In a global vision, we observe that those creators who belong to the Mid-century Generation (Generación de medio siglo) deteriorate the idea of the childhood as a wonderful age; rather, they characterize it in numerous cases as a lonely time, sometimes even a neglect one. Childhood as a topic has had various reformulations since the I950's. Among them, the input of this talented writer from Zacatecas takes us away from the typical images of childhood and allows us to elaborate interpretations that reveal how "the home's kings" not always bring happiness nor fully enjoy the first years of their lives.

Keywords: Amparo Dávila, Mexican narrative, Childhood, Innocence, Loneliness.

Recibido: I de enero de $202 \mathrm{I}$ Aceptado: 27 de marzo de $202 \mathrm{I}$ https://dx.doi.org/I0.I 5 I74/rv.vi3i28.5 I6

\section{El medio siglo: la irrupción de las niñas y los niños}

\section{A mparo Dávila es parte de la llamada Generación de medio Asiglo. Mucho se ha escrito sobre este nutrido contingente que surgió en el escenario literario mexicano en la década de 1950; la}


crítica especializada, ya sea en estudios particulares o de conjunto, coincide en un lugar común: destacar el aporte de los miembros de tal promoción por la renovación que hicieron de la literatura mexicana. Alfredo Pavón, uno de los principales estudiosos de la narrativa breve, además de indicar la valía del grupo, puntualiza aspectos que conviene tener presentes. Cito unas líneas de su "Prólogo" a la antología Cuento mexicano moderno:

Incrustados entre los expresionistas, pero miembros más bien de la generación de medio siglo, Carlos Fuentes, Carlos Monsiváis y José Emilio Pacheco son precoces narradores que habrán de unirse, entre otros, a Amparo Dávila, Guadalupe Dueñas, Vicente Leñero, Jorge López Páez, Sergio Pitol, Emilio Carballido, Sergio Galindo, Juan Vicente Melo, Juan García Ponce, Inés Arredondo, Rosario Castellanos, Emma Dolujanoff, Jorge Ibargüengoitia, Hugo Hiriart, Eraclio Zepeda, Juan Tovar, Salvador Elizondo, para producir un cuento insolente y gozoso, pleno de desconfianza en el progreso industrial, de análisis de la compleja naturaleza humana, de pensar sobre los mecanismos del arte de narrar, de pérdida de las fronteras genéricas y discursivas, de aglutinamiento de la anécdota, de perspectivismo complejo, de metaficción e intratextualidad. No les son ajenos, además, el mundo juvenil y la problemática femenina, el rechazo del predominio del final sorpresa, el rejuego con el minicuento (2000: XVII).

En este breve y conciso panorama, Pavón expone ciertos rasgos que caracterizan las obras de algunos autores, incluida Dávila:

Otros más (García Ponce, Melo, Arredondo, Dávila, Dueñas, Beatriz Espejo) se inclinan por el cuento intimista, afecto al análisis psicológico y a los voraces incendios interiores. Centro de este mundo íntimo es el erotismo, ingrediente cercado por la soledad, 
lo absurdo, los actos rituales y el vacío humano. Les interesa sobremanera la naturaleza esencial del hombre y la mujer concretos, sin importarles si estos viven en la provincia, la urbe o en cultura ajenas a la suya (2000: XVIII).

Gracias al trabajo sobre el cuento mexicano que Pavón ha realizado durante décadas, consigue trazar líneas generales que demarcan las tendencias y los temas practicados por escritores (desde los principales hasta los poco conocidos) pertenecientes o no a grupos o generaciones que han conformado nuestra tradición cuentística, como lo hemos constatado con lo que detalla de la Generación de medio siglo. No obstante, es posible matizar aún más los intereses de los creadores o los bloques temáticos. Propongo como ejemplo las representaciones de la infancia, que se podrían considerar un segmento de lo que Pavón denomina "el mundo juvenil", aunque en estas líneas (y en otros trabajos al respecto) sugiero que dicho tema y sus motivos merecen un espacio propio en los estudios grupales e individuales sobre la narrativa mexicana del siglo xx. Son escasas las investigaciones (algunas de ellas valiosas) que dan cuenta de esta veta que todavía no hemos estudiado lo suficiente en nuestras letras. Para dimensionar el alcance de dichas representaciones, expongo un breve panorama de las apariciones infantiles previas a los cuentos de Dávila.

Luego de que algunos menores protagonizaran relatos en la primera mitad del siglo pasado (en las obras de Mariano Silva y Aceves, Nellie Campobello, Agustín Yánez y César Garizurieta, entre otros), en los cincuenta surge una buena cantidad de textos donde los infantes son las figuras principales. Muestra de ello son la novela Retrato de una niña triste, que marca el debut de Olivia Zúniga como prosista en 1951 y donde la narradora adulta hace un esfuerzo por reconstruir a esa nińa que fue y a la que siente como otra, ajena; ese mismo año Sergio Galindo publica La má- 
quina vacía, libro de cuentos donde los primeros cinco se tiñen de infancia y de sentimientos como la soledad y el desengaño. En 1954 el reconocido dramaturgo Sergio Magaña le otorga protagonismo en su novela El molino del aire a Sergio, niño de seis años de gran sensibilidad que cuenta con el afecto y comprensión de su madre, pero con la intolerancia y malos tratos de su padre; en ese año debuta Elena Poniatowska con Lilus Kikus, donde la inquieta niña del mismo nombre descubre el mundo y aturde a sus padres con la infinidad de preguntas que siempre se le ocurren. Un año después, aparecen dos libros de cuentos: La muerte tiene permiso, de Edmundo Valadés, y Los mástiles, de Jorge López Páez, que nos presentan varios personajes infantiles que sufren ante la incomprensión de los demás; del primer libro, el relato más interesante es "La infancia prohibida" (donde un protagonista huérfano padece la convivencia con los tíos que lo acogen), mientras que del segundo los tres textos que lo conforman presentan a chicos sensibles que reproducen, mediante juegos, las reglas del mundo adulto. Al año siguiente, dos relatos del libro La noche alucinada, de Juan Vicente Melo, trabajan la noción de la inocencia infantil, la cual ya ha sido explorada por los autores previos al medio siglo. En 1957, Rosario Castellanos nos entrega Balún Canán, novela protagonizada y narrada por una niña de siete años que debe arreglárselas en un mundo donde su hermano menor, el único hijo varón de la familia, es el que tiene todos los privilegios. Arribamos a 1958 y dos títulos llaman nuestra atención: el libro de cuentos Tiene la noche un árbol, de Guadalupe Dueñas, donde "La tía Carlota" ocupa un lugar especial entre varios relatos con menores de edad como figuras centrales, y la novela El solitario Atlántico de Jorge López Páez; algo que llama la atención es la soledad que sufren tanto las y los protagonistas de los relatos de Dueñas y de la narración de López Páez. Un año antes de que termine la década, Sergio Pitol aporta cuentos para el corpus que me interesa destacar: "Victorio Ferri 
cuenta un cuento" (con uno de los primeros casos de niños proclives a la maldad) y "La casa del abuelo" (donde, como en cuentos de Dueñas y Valadés, un protagonista padece a una tía); también en 1959 aparece la primera colección de cuentos de la zacatecana, Tiempo destrozado, con lo cual se une a las varias reformulaciones sobre la infancia que se multiplicaron en la década.

Tras el recuento anterior, no resulta novedoso que niños y nińas aparezcan en la narrativa de Dávila, incluso están lejos del protagonismo que se les otorga en otras obras, pero es posible observar cómo su presencia refuerza un par de motivos en la narrativa mexicana que vienen de décadas previas y se consolidan en los años cincuenta: la soledad y el miedo; asimismo, destaca el empleo de menores de edad por parte de la autora para establecer constantes en su prosa. Encuentro cinco situaciones donde está involucrada la niñez, ya sea con personajes que tienen distintos grados de participación en la historia o en determinadas valoraciones sobre esa etapa de la vida, a saber:

1. La infancia como inocencia.

2. El niño/la nińa como un ser pusilánime.

3. Los menores como parte del matrimonio para cumplir con la convención social.

4. Los niños como "obstáculo" para el orden y la limpieza del hogar.

5. La infancia como una etapa de soledad y miedo.

Algunos puntos apenas se mencionan, mientras otros aparecen con recurrencia o incluso se prestan para un desarrollo mayor. Sin que el orden de los aspectos indique una jerarquía, reflexiono sobre ellos y dejo al final la infancia impregnada de tristeza y temores. 


\section{"Los niños son un premio, una dádiva"}

Fernando Cabo, en su libro Infancia y modernidad literaria, recuerda a un célebre personaje de la tradición hispánica, Lázaro de Tormes, para explicar dos nociones sobre la niñez que vienen desde la antigüedad y que encontramos muy arraigadas en la concepción de la infancia en Occidente. Veamos:

Como niño, Lázaro tiene dos atributos básicos. La simplicidad es uno de ellos. De la simpleza despierta a la vida adulta, tras el cabezazo, el niño que "simplemente" se había allegado a la piedra. [...] El otro es la pusilanimidad, la falta de firmeza, reconocida al dejar constancia de la delación de su padrastro. Son elementos que remiten a la imagen clásica del niño. Plinio hacía de la simplicitas la cualidad prototípica del puer. [...] También cuando Lázaro, tras su violento despertar, toma la primera determinación de su corta vida [...] su comportamiento se acomoda a una idea de profunda raíz en la cultura occidental: la que se remonta a Aristóteles cuando en su Ética a Nicómaco considera la capacidad de elección ajena tanto a los niños como a los animales (2001:16).

La simpleza y la pusilanimidad caracterizan desde hace siglos a la infancia. La primera noción no es difícil emparentarla con la inocencia: Lázaro no es tonto, pero carece de experiencia; podríamos decir que le falta malicia. En cuanto a la capacidad de elección, es necesario que los menores sean guiados por sus padres o tutores (como le sucede a Lázaro, sobre todo con su primer amo), de quienes se esperan las enseñanzas que provean al niño de los principios y conocimientos básicos para desenvolverse en el mundo. En suma, los niños, seres inocentes, necesitan orientación del adulto mientras no sean capaces de valerse por sí mismos. Ahora bien, en el tránsito de las ideas de la antigüedad sobre la infan- 
cia a las que surgieron en la modernidad, notamos que el niño dejó de ser un "pequeño adulto" para convertirse paulatinamente en un sujeto con necesidades específicas, por lo cual la inocencia (que antes era un defecto) se vuelve una cualidad muy apreciada por los adultos. Surge la conciencia de la "infancia, el niño, como otro. [...] La conformación de la infancia como realidad influyente exige concebirla como diferencia. De ahí extraerá precisamente la extraordinaria fuerza simbólica que va aparejada a su representación, o simplemente a su atractivo imaginario, en la cultura y, de modo particular, en la literatura moderna” (Cabo, 2001: 31). Precisamente de su "fuerza simbólica" y de los lugares comunes que genera desde el Romanticismo, se han alimentado infinidad de narraciones de diversas tradiciones literarias. Las representaciones en los relatos de Dávila no son ajenas a este fenómeno, aunque es necesario reconocer que la autora muestra matices poco explorados en la década de 1950, mismos que enriquecen las propuestas de su narrativa.

La inocencia puede ser ambivalente en los textos de Dávila y funciona para caracterizar de manera positiva o se emplea para deplorar cierta actitud o conducta; en ambos casos, los personajes son infantilizados por otro personaje. Ilustro esta situación con "La quinta de las celosías", donde Jana, al recibir a Gabriel por primera ocasión en su casa (y única al parecer), le relata cómo era la vida con sus padres:

—Aquí se sentaba siempre papá, a veces se quedaba dormido, ¡me enternecía tanto!, vivía cansado, trabajaba mucho, para que nada nos faltara a mamá y a mí, decía siempre cuando le reprochábamos, ¡pobre papá!... a veces jugaba ajedrez con el Dr. Hoffman, los domingos en la tarde; mamá servía el té y las pastas, después cogía su bordado, siempre bordaba flores y mariposas, flores de durazno y violetas; de cuando en cuando dejaba la costura y ob- 
servaba a papá jugando con el Dr. Hoffman, lo miraba con gran ternura como si hubiera sido un niño, su niño (2003: 42-43).

A la chica la enternecía ver a su padre dormido, mientras que su madre, cuando él jugaba ajedrez, lo veía como "su niño". En este relato también encontramos otra constante de varias historias de Dávila: las madres ven a sus hijas como niñas y procuran protegerlas para preservar su inocencia: "por la tarde fuimos a tomar helados y después al teatro, mamá comentó que la obra era un poco atrevida para una nińa; 'ya es una joven', agregó papá con una sonrisa, 'está bien que vaya sabiendo algunas cosas'” (2003: 45). A veces, molesta descubrir la propia infantilización; tomemos por caso la reacción de Gabriel ante la fría actitud de Jana:

[...] todo falso, fingido, planeado, actuado tal vez. Sintió de pronto un enorme disgusto de sí mismo y el dolor de haber sido tan torpe, tan ciego, tan iluso; dolor de su pobre amor tan niño. La miró con rencor, casi con furia, con furia, sí, desatada, de pronto desenfrenada y terrible. Ella sonreía con aquella sonrisa que bien conocía, aquella sonrisa inocente que tanto lo había conmovido y... (2003: 46).

Gabriel "despierta” de su simpleza (causada por el amor) y cree descubrir la verdad sobre la chica y sus sentimientos. En la misma cita identificamos que lo enoja su "amor tan nińo", pero lo enamoró la "sonrisa inocente" de Jana. La inocencia resulta, pues, ambivalente.

En "La celda" nos percatamos del cambio de actitud de María, la protagonista, quien orillada por los miedos nocturnos que la aquejan abandona en corto tiempo la inocencia y hasta pusilanimidad que proyectaba al resto de la familia: "La señora Camino se mostraba muy contenta de ver que María pasaba los días 
ocupada, 'esa niña siempre fatigada y sin ánimo para nada ahora está activa constantemente" (2003: 52). La idea de escapar a las terribles noches que la torturan impulsa a María a ser atenta con su pretendiente: "Luchando contra su natural timidez, comenzó a ser amable con él y a conversar. Esta nueva reacción de María fue recibida con bastante agrado no solo por José Juan Olaguíbel, sino por toda la familia, lo cual facilitaba las cosas" (2003: 53). Lo que para los demás significa que María está creciendo y madurando, en realidad es una huida de los miedos nocturnos.

Otra "niña” a la cual se le reprocha su inocencia es a Carmen, la figura central de "El desayuno", pues que un sueño la vuelva pusilánime es inaceptable para su padre:

Carmen puso los codos sobre la mesa y apoyó la cara entre las manos.

- Tuve un sueño espantoso — dijo con voz completamente apagada.

— ¿Un sueño? - preguntó la madre.

—Un sueño no es para ponerse así, niña — dijo el padre-. Anda, desayúnate.

Pero ella parecía no tener la menor intención de hacerlo y se quedó inmóvil y pensativa (2002: 80).

Hemos visto cómo Dávila configura personajes femeninos pusilánimes, pero los masculinos no escapan de tal caracterización. Quizá uno de los más representativos es el protagonista de "Un boleto para cualquier parte". Marcos rehúye de todas las responsabilidades y de las hipotéticas complicaciones siguiendo una enseñanza materna: “'Los amigos esclavizan, hijo.' Tenía razón su madre, ya no disponía de libertad ni para irse a su casa cuando quisiera" (2003: 25). Aunque no encontremos una marca textual de infantilización en el cuento, las acciones que Marcos imagina o ejecuta 
impulsado por los deseos de otros, así como la falta de firmeza en sus decisiones de adulto, nos lo presentan como un "menor" que se siente culpable ante la sociedad y, sobre todo, ante su madre.

En otra vertiente de la infancia en la prosa de Dávila, la descendencia aparece como un requisito más para los adultos que cumplen con las convenciones sociales: un matrimonio debe tener hijos para realizarse. Sin embargo, en otra ambivalencia presente en los cuentos de la zacatecana, los niños también son motivo de desorden en el hogar, de trabajo para las madres, algo que no suelen padecer los esposos. Felicidad y pesar (a veces en el mismo cuento) en la representación de los nińos. Desde el primer libro encontramos historias que ilustran lo anterior. Por ejemplo, la anécdota de "Muerte en el bosque" aunque está focalizada en buena medida en la mente de un personaje masculino, nos deja "escuchar" a su demandante esposa: "-Y mientras tanto, yo aquí volviéndome loca. Ya no soporto a los niños brincando sobre las camas y destruyéndolo todo, porque no tienen dónde jugar. (Había hecho todo por malcriar a los niños y ahora se quejaba) - Te exijo que busques un departamento inmediatamente" (2003: 70).

No solo ella padece a los nińos, pues el varón, mientras espera a que le muestren un departamento, piensa en cómo sería su vida si huyera de la ciudad y de su cotidianidad; más aún, convertirse en un árbol sería lo ideal: "y él en el bosque sin importarle nada, sin oír ya sonar papeles y cajones y cosas... descansando de aquella fatiga de toda su vida, de los tranvías, de las calles llenas de gente y de ruido, de la prisa, de los relojes, de su mujer, de la horrible vivienda, de los niños" (2003: 74). Sin embargo, su ensońación lo lleva a un punto donde su soledad sería insoportable y no podría recuperar a su mujer ni a sus hijos: “-Ya me estoy acordando dónde guardé el papelito — ... ver pasar un día a sus hijos y a su mujer, y él sin poder gritarles - Soy yo, no se vayan- ellos no se detendrían bajo su sombra, ni lo mirarían siquiera, no les comunicarían 
nada su emoción ni su alegría” (2003: 75). Aunque son molestos, su mujer e hijos parecen ser el último asidero de un hombre que, al igual que el protagonista de "Un boleto para cualquier parte", al final termina huyendo ante la presión familiar y social.

Si pensamos en la "necesidad" de una familia, "Tina Reyes" presenta a una protagonista que envidia a una amiga que lo tiene todo, incluidos los hijos que representan más trabajo domestico: “'Ojalá y Rosa esté bien', la semana anterior la había visto muy cansada, era natural con tanto trabajo, ella sola para todo el quehacer y atender a los niños y a Santiago [...] tenía suerte Rosa: un marido como Santiago, sus hijos, una casita, viéndolo bien era mucho tener, en cambio ella" (2002: 111-112). Tina aspira a emular a Rosa (pese a que esta no vive en las mejores condiciones) porque la perspectiva de envejecer sola la desconsuela. Cualquier sacrificio, incluidos los hijos, es más soportable que la soledad:

[...] ¿cómo sería tener un departamento, cómo sería tener marido, hijos, un hombre que la abrazara y le dijera Tina con voz cariñosa?, aunque tuviera que trabajar tanto como Rosa, pero sabiendo que al anochecer él llegaría; cenar juntos platicando de todas las cosas del día, de los niños, ver después la televisión y, si no había, por lo menos oír un rato el radio, después dormir con la cabeza apoyada en el hombro de él, ya no sentiría tanto frío por las noches, dormiría tranquila oyéndolo respirar, ver crecer a los niños, oírlos decir mamá... (2002: 113).

Su candidez no solo es palpable por la idealización del matrimonio: sin experiencia, se sorprende cuando un hombre le dirige la palabra y la acompaña cuando ambos bajan del camión. De nuevo, aparece la "inocencia infantil": "Tina se ruborizó y fue a sentarse en una mecedora. Tenía todo el aire de niña sorprendi- 
da en una travesura. Comenzó a mecerse y a sonreír complacida. ¡Qué bien se sentía siempre que veía a Rosa!” (2002: 116-117).

De vuelta con la noción de los niños como parte del matrimonio, otro caso es "El entierro", donde el protagonista yace en una cama de hospital y repasa los acontecimientos importantes de su vida; uno de ellos, la vida en pareja y con hijos:

El alejamiento había surgido a los pocos años de matrimonio. Él no podía atarse a una sola mujer, era demasiado inquieto, tal vez demasiado insatisfecho. Ella no lo había comprendido. Reproches, escenas desagradables, caras largas... hasta que al fin acabó por desentenderse totalmente de ella y hacer su vida como mejor le complacía. No hubo divorcio; su mujer no admitía esas soluciones anticatólicas, y se concretaron solo a ser padres para los hijos y a cumplir con las apariencias (2002: 132-133).

Antes que verse criticados por su círculo social, los esposos acuerdan simular ante todos que son buenos "padres para los hijos". Soportar un matrimonio infeliz conviene más a la proyección de una imagen que a la protección de los hijos.

Cierro este apartado con dos ejemplos de Árboles petrificados (1977): el primero, los hijos como desorden; el segundo, cuando estos dejan de ser una bendición. "La noche de las guitarras rotas" presenta a las hijas de la protagonista como un atentado contra el orden y los objetos ajenos; lo anterior ocurre en una tienda de instrumentos musicales donde la mamá, por platicar con la empleada que atiende, descuida a sus nińas y estas aprovechan para alterar la tranquilidad del local, al grado que sale el dueño a poner orden:

Ninguna de las dos, ni ella ni yo, nos habíamos dado cuenta de que mientras platicábamos tan entusiasmadas mis hijas probaban una guitarra tras otra, o bien sonaban un bongó con una mano y 
con la otra una maraca, o ensayaban los violines sacándoles sonidos destemplados, cuando una voz como un trueno, o un rugido, cortó de golpe nuestro diálogo, con tal violencia y en una forma tan sorpresiva, que yo sentí como si aquella interrumpida conversación quedara ahora relegada a un remotísimo pasado.

— ¡Dejen allí, nińas, dejen, dejen las cosas en su lugar, no toquen más, que no toquen nada! ¿Me oyen? ¡Han manoseado todo, desarreglándolo, ensuciándolo, estropeándolo, dejando pintados sus dedos mugrosos, y ella allí, mirando sin importarle nada! (2009: 189).

El hombre furioso se une a otros adultos que "padecen" las numerosas incomodidades de lidiar con infantes, frecuentemente representados como una molestia en los cuentos de Dávila. Son un pesado requisito para cumplir con las convenciones sociales.

La protagonista de "El último verano" ha desempeñado sin queja su rol de madre, pero llega el momento en que este deja de ser algo bello:

Por las noches y un poco entre sueños Pepe la oía llorar o la sentía estremecerse, pero él apenas si se daba cuenta de que ella no dormía. Era natural que Pepe descansara a pierna suelta, ¡claro!, él no tendría que dar a luz a un hijo más, ni que cuidarlo, "los niños son un premio, una dádiva”, pero cuando se tienen cuarenta y cinco años y seis hijos otro hijo más no es un premio sino un castigo porque ya no se cuenta con las fuerzas ni alientos para seguir adelante (2009: 207).

Es lógica la molestia de la protagonista y no sabemos hasta qué punto, además de la edad y la cantidad de hijos, se ha repetido la rutina que hemos visto con otros personajes femeninos que han 
cumplido su sueño de ser madres: trabajo doméstico sin el apoyo del varón, labor que día tras día desgasta física y emocionalmente.

Luego de los ejemplos anteriores, considero que la reiterada representación de los niños como desorden latente y la inevitable labor para la madre conllevan un distanciamiento de la imagen estereotipada de los hijos como la felicidad del hogar; incluso, cuando tal imagen surge en concordancia con el lugar común, es consecuencia de la idealización efectuada por los personajes femeninos que casi tienen como obligación la maternidad y el hogar en su horizonte de expectativas. La crítica emprendida por Dávila es poderosa, valiéndose de la erosión de imágenes usuales que en un primer momento invocan las bondades de la infancia, para luego ponerlas en duda.

\section{"La soledad a cuestas siempre"}

Existen otros casos en la narrativa de Dávila donde la infancia o los niños adquieren mayor relevancia en la configuración de los relatos; es oportuno revisar "El huésped" y "Arthur Smith" en un primer momento, para luego enfocarnos en "Tiempo destrozado", "Alta cocina" y "El jardín de las tumbas". Los primeros muestran elementos ya vistos, como la inocencia, los niños como desorden y parte de un matrimonio aparentemente exitoso; no obstante, la autora emplea esos aspectos como parte de un andamiaje más complejo.

"El huésped", cuento incluido en diversas antologías y estudiado desde varias posibilidades críticas, merece un par de consideraciones desde la óptica que proponen estas líneas. Quizá resulte ocioso reseńarlo, pero me permito retomar algunos elementos para conducir mis reflexiones. La historia es narrada por la protagonista, una mujer que explica: 
Llevábamos entonces cerca de tres años de matrimonio, teníamos dos niños y yo no era feliz. Representaba para mi marido algo así como un mueble, que se acostumbra uno a ver en determinado sitio, pero que no causa la menor impresión. Vivíamos en un pueblo pequeńo, incomunicado y distante de la ciudad. Un pueblo casi muerto o a punto de desaparecer (2003: 17).

Los estudios que subrayan la terrible y humillante situación vivida por la protagonista tienen un primer punto de arranque con estas líneas; en mi caso, señalo cómo, de nueva cuenta, los hijos figuran como un elemento más para cumplir con el matrimonio convencional. Posteriormente, la narradora describe las actividades que fueron habituales: "[y]o me levantaba siempre muy temprano, vestía a los niños que ya estaban despiertos, les daba el desayuno y los entretenía mientras Guadalupe arreglaba la casa y salía a comprar el mandado" (2003: 18). Aunque son nińos pequeños y no constituyen el "obstáculo" que ya hemos visto en otros relatos, una vez más “entorpecen” la limpieza y el orden de la casa; también, aunque con un tono nostálgico, la madre evoca el trabajo que le implicaban los menores: "Recuerdo cuánto me gustaba, por las tardes, sentarme en uno de aquellos corredores a coser la ropa de los niños, entre el perfume de las madreselvas y de las bugambilias" (2003: 18). Definitivamente son más llevaderas las labores relacionadas con los infantes gracias a que contaba con la ayuda de Guadalupe, trabajadora doméstica.

El orden es alterado por la nefasta criatura que atemoriza a niños y mujeres en la casa, salvo al esposo, con todo lo que ello simboliza. Aun cuando el huésped es una molestia, la narradora recuerda los esfuerzos por conservar la rutina, en cuyo centro se encontraban sus hijos: "Cuando los niños se dormían, Guadalupe me llevaba la cena al cuarto. Yo no podía dejarlos solos, sabiendo que se había levantado o estaba por hacerlo. Una vez terminadas 
sus tareas, Guadalupe se iba con su pequeño a dormir y yo me quedaba sola, contemplando el sueño de mis hijos” (2003: 20). Hasta aquí, creo, a pesar de la tensión aún no se rompía el orden: la señora de la casa cuidaba a sus hijos y velaba por su sueño, mientras Guadalupe hacía lo propio. Poco más adelante, el ataque al elemento más vulnerable termina por caldear los ánimos:

Vuelvo a sentirme enferma cuando recuerdo... Guadalupe había salido a la compra y dejó al pequeño Martín dormido en un cajón donde lo acostaba durante el día. Fui a verlo varias veces, dormía tranquilo. Era cerca del mediodía. Estaba peinando a mis niños cuando oí el llanto del pequeño mezclado con extraños gritos. Cuando llegué al cuarto lo encontré golpeando cruelmente al niño. Aún no sabría explicar cómo le quité al pequeño y cómo me lancé contra él con una tranca que encontré a la mano, y lo ataqué con toda la furia contenida por tanto tiempo. No sé si llegué causarle mucho daño, pues caí sin sentido. Cuando Guadalupe volvió del mandado, me encontró desmayada y a su pequeño lleno de golpes y de araños que sangraban. El dolor y el coraje que sintió fueron terribles. Afortunadamente el niño no murió y se recuperó pronto (2003: 21).

Este pasaje detona el enojo y la sororidad de ambas mujeres por varias situaciones: a) la víctima es el niño más pequeño, b) la narradora defiende al hijo de su empleada a costa de descuidar a los suyos, c) ambas reconocen una amenaza en común y, si bien puede atentar contra ellas, la prioridad, a partir del incidente, la constituyen los niños. Desde ese momento, "[m] is niños estaban atemorizados, ya no querían jugar en el jardín y no se separaban de mi lado" (2003: 22). Más aún: ya no son sus hijos y el de la empleada, se ha establecido un sentido comunitario: 
Guadalupe y su niño durmieron en mi cuarto y por primera vez pude cerrar la puerta. [...] Guadalupe y yo pasamos casi toda la noche haciendo planes. Los niños dormían tranquilamente. De cuando en cuando oíamos que llegaba hasta la puerta del cuarto y la golpeaba con furia... [...] Al día siguiente dimos de desayunar a los tres niños y, para estar más tranquilas y que no nos estorbaran en nuestros planes, los encerramos en mi cuarto (2003: 23).

Más allá de la interpretación global del cuento, del conflicto entre los esposos o de la naturaleza del "huésped", notemos cómo las mujeres se unen para proteger a los seres inocentes e indefensos. Los otros significados (los niños como desorden y como requisito del matrimonio) ceden ante la fuerza simbólica de la infancia, como explica Cabo, y es lo que las impulsa a encerrar al ser que ha vuelto insoportable la vida en esa casa. Tras exponer lo anterior, tengo puntos de encuentro con la opinión de Maricarmen Pitol, quien resume los motivos que tuvieron las dos mujeres para actuar: "Cólera ante el temor impuesto, la posibilidad de la muerte, la niñez maltratada, el dolor, el cansancio de dos madres" (1996: 296-297).

"Arthur Smith" nos presenta a un matrimonio donde el esposo tiene un orden inquebrantable y la mujer se dedica al hogar y, por supuesto, a los hijos. Dávila, para caracterizar la vida ordinaria de Mrs. Smith, presenta a los niños como ya los hemos visto:

Rompieron la botella de la leche y el frasco de la mermelada; Mrs. Smith les propinó un buen manazo a cada uno y los sacó al jardín para que la dejaran en paz. "No es posible poner en orden una casa, ni hacer nada, con niños corriendo por todos lados", decía siempre Mrs. Smith. Y todos los días tan pronto desayunaban iban a jugar al jardín. Entonces ella comenzaba la diaria rutina del hogar (2002: 8-9). 
Las primeras señales de lo que se avecina para la esposa comienzan cuando el metódico Mr. Smith altera su rutina en el desayuno y posteriormente no llega a su trabajo, incluso se desconoce su paradero; tal situación la preocupa, aunque consigue desarrollar sin inconvenientes parte de su jornada. La sorpresa será cuando busque a sus hijos para que entren a la casa a comer: "Apenas podía dar crédito a lo que sus ojos veían: allí estaba Arthur con los chicos, jugando a las canicas, en mangas de camisa y sin corbata. El saco, el portafolio, el sombrero y el paraguas tirados en la hierba. Allí había estado, toda la mańana, con los niños, jugando en el jardín. No había ido a la oficina por quedarse a jugar a las canicas" (2002: 14-15).

Arthur tiene dificultades para contar las canicas, y apenas se da cuenta que no tiene plato en la mesa comienza a llorar. Dávila infantiliza a otro personaje, aunque en este caso lleva la propuesta al extremo, y según algunas interpretaciones se aleja de una solución realista debido al cambio operado en el hombre de la casa: "Mrs. Smith se apoyó en la estufa para no caer. Sentía que, por momentos, se iba a desplomar, que todo giraba en torno a ella y que un enorme dolor la desgarraba. Y un sollozo ahogado, ronco, estremeció su cuerpo. Supo que había perdido a Arthur Smith; que frente a ella, sentados en la mesa, había tres niños" (2002: 16). De acuerdo con Pitol, Arthur "ha sufrido una transformación, se ha trocado en niño [...] ha cambiado [su mundo], ha situado las cosas en un orden nuevo, agradable para él” (1996: 289-290). Según Pitol, el señor Smith huye de su realidad y se refugia en el juego, en la infancia, de ahí que ella considere que "la sociedad rígida, de reglas establecidas que llevan al hombre a quebrantar su vida y buscar un sitio seguro para refugiarse. Y entonces, ante tal angustia, ¿por qué no acudir a la infancia?” (1996: 285) Comparto esta reflexión, volver a la infancia para refugiarse (la cual abre el estudio de Pitol sobre la infancia en la obra de Dávila), de manera parcial. 
Coincido en que es el camino que emprende el señor Smith, no así los protagonistas de "Tiempo destrozado" y de "El jardín de las tumbas" (tres de los cuatro textos que analiza Pitol).

Cito el inicio del relato que da título al primer libro de la zacatecana: "Primero fue un inmenso dolor. Un irse desgajando en el silencio" (2003: 92). No hay certidumbre del origen del dolor, tampoco si sobreviene un desmayo, por ejemplo. Tanto Pitol como Berenice Romano ${ }^{1}$ coinciden en señalar el carácter onírico de los fragmentos que vienen a continuación; ahora bien, esto ocurre una vez que se ha consumado ese "instante sin fin" que padece la narradora adulta, aseveración de mi parte que se aleja de la afirmación de Pitol: "la niña hila cuatro relatos simbólicos sin relación aparente" (1996: 293). ${ }^{2}$ Si se tratara de una menor, la caracterización resultaría inconsistente, primero, por el léxico empleado para referir las cinco historias (y no cuatro, como señala Pitol) y, segundo, por las limitaciones cognitivas y perceptuales (propias de un infante) que presentaría la mente figural, de ahí que resulta más conveniente identificar a una adulta, como consigna Romano, que "yuxtapone tiempos y espacios fragmentados"; así la narradora lo mismo relata dos momentos de infancia y otros tres de vida adulta. ${ }^{3}$ En los que se centran en la niñez, llama la atención que en el

${ }^{1}$ "En 'Tiempo destrozado' encontramos] un fluir de narración, una secuencia onírica, que se rompe a cada paso, de forma cíclica, y que presenta la historia como una cadena de pedazos que representa la voz de un personaje. Por medio de oraciones breves, Dávila yuxtapone tiempos y espacios fragmentados que hablan de una poética del tiempo que trabaja como basamento del resto de sus relatos" (Romano, 2009: 117).

${ }^{2}$ Añade Pitol: "El contenido manifiesto de estos, que suponemos son sueńos, se nos presenta oscuro, lleno de fantasmas, que tendremos que ir interpretando para conocer su contenido latente" (1996: 293).

${ }^{3}$ No omito destacar que en las últimas líneas del fragmento que cierra el relato, la narradora menciona que otra mujer lleva a un nińo pequeño, mujer que "[t]ambién era yo aquella otra"; ella/la otra comienza a ahogar al niño con un 
primero aparezcan dos, incluso tres, motivos que tomaron fuerza en las reformulaciones realizadas en el medio siglo: soledad, miedo y orfandad:

Brinqué adentro del estanque. Cuando llegué al fondo solo había manzanas y peces tirados en el piso; el agua había saltado fuera del estanque y, llevada por el viento, en remolino furioso, envolvió a papá y mamá. Yo no podía verlos, giraban rodeados de agua, de agua que los arrastraba y los ocultaba de mi vista, alejándolos cada vez más... sentí un terrible ardor en la garganta... papá, mamá... papá, mamá... yo tenía la culpa... mi papá, mi mamá... Salí fuera del estanque. Ya no estaban allí. Habían desaparecido con el viento y con el agua... comencé a llorar desesperada... se habían ido... tenía miedo y frío... los había perdido, los había perdido y yo tenía la culpa... (2003: 93-94).

El otro fragmento, donde la protagonista vuelve a verse como niña, también resulta angustioso y coincide con las propuestas que otros autores dejan ver en las narraciones sobre la infancia: esta no es un periodo de felicidad plena, sino un tiempo que puede estar impregnado de soledad, miedo e incluso orfandad. Se suman a los ejemplos previos los protagonistas de "Alta cocina” y "El jardín de las tumbas", dado que sufrieron (¿y sufren?) pasajes de su infancia. Aquí tomo distancia con la idea de Pitol, pues no considero que los adultos acudan a la infancia ante la angustia que experimentan en su presente: al crecer, es justamente de pasajes dolorosos de la niñez de lo que han intentado escapar.

pañuelo en la boca, por lo cual “[s]entí profundo dolor por el niño, ¡mi pobre niño!, y di un grito, uno solo. El pańuelo con que me tapaban la boca era enorme". De nuevo una ambivalencia, en este caso en el plano onírico: el daño que provoca al niño, su nińo, es el mismo que ella padece (Dávila, 2003: 100). ¿Se infantiliza al sentirse indefensa y vulnerable, como el niño al que ataca? 
Tanto en "Tiempo destrozado", como en los dos cuentos que revisaré a continuación, existe un resorte mnemotécnico, involuntario, que lleva al adulto a ciertos momentos de la infancia. Mientras que en el relato anterior se recuperan momentos oníricos, en "Alta cocina" el detonante es la lluvia que golpea los cristales de las ventanas y las gotas que se asemejan a "cientos de pequeños ojos pegados" (2003: 67); en "El jardín de las tumbas", el protagonista tiene "acceso" a su pasado gracias al hallazgo de un diario que le trae a su insatisfactorio presente los terribles recuerdos nocturnos que lo aquejaban y que, incluso, condicionan en cierta medida su vida adulta. Procedo a ver cada caso.

Partamos de una situación interesante en "Alta cocina": no existen marcas que identifiquen plenamente al yo narrado como un infante; pese a ello, encuentro algunos rasgos que delatan cierta inocencia y pusilanimidad, que pueden ser propios de un nińo, como los que hemos constatado en otros relatos de Dávila. El primer ejemplo es la empatía con el sufrimiento de los caracoles, a tal grado, que el protagonista los "escucha":

Desde mi cuarto del desván los oía chillar. Siempre llovía. Sus gritos llegaban mezclados con los ruidos de la lluvia. No morían pronto. Su agonía se prolongaba interminablemente. Yo pasaba todo ese tiempo encerrado en mi cuarto con la almohada sobre la cabeza, pero aun así los oía. Cuando despertaba, a medianoche, volvía a escucharlos. Nunca supe si aún estaban vivos, o si sus gritos se habían quedado dentro de mí, en mi cabeza, en mis oídos, fuera y dentro, martillando, desgarrando todo mi ser (2003: 67).

La identificación de los niños sensibles con seres indefensos (los animales, por ejemplo) no es ajena a otras obras del medio 
siglo. ${ }^{4}$ En otro ejemplo, que podemos asociar con la pusilanimidad, recordemos que cuando mandaron al protagonista a comprar caracoles decidió mentir para salvarles la vida, aunque cuando lo descubren la cocinera es quien los trae en grandes cantidades; ante la impotencia de no salvarlos (no actúa), padece con el sufrimiento de los moluscos, incluso en el presente de enunciación: "Pero no había misericordia en aquella casa. Nadie se conmovía ante aquella crueldad. Sus ojos y sus gritos me seguían y, me siguen aún, a todas partes" (2003: 67).

Como indica Muñoz (2008, 2018, 2018a) en distintos trabajos, los caracoles no "chillan", pero en la mente del personaje central así ocurría y, como una extrańa fijación, el narrador adulto asocia las gotas de agua adheridas en las ventanas con los ojos que lo siguen mientras sufren. No paso por alto la impresión tan honda que deja la elaboración del guiso en la mente figural y cómo la lluvia funciona como detonador para que, una vez más, regresen esos momentos.

La parte medular de "El jardín de las tumbas" es el "reencuentro" del narrador, adulto, con su voz juvenil, la cual se halla contenida en un diario que redactó en dos momentos, unos años de la infancia y otros de la adolescencia. El primero es el que me interesa para estas líneas, y el cual Dávila resalta en cursivas. Esta parte del manuscrito da cuenta de los días de vacaciones en familia en un sitio poco habitual: un convento abandonado. Bajo la protección de la luz matutina, aquel lugar era ideal para todos los juegos que se le ocurrían al protagonista y a sus hermanos, sin embargo, al oscurecer: "Entonces empieza la noche del terror para mi y no sé, ni

\footnotetext{
${ }^{4}$ Como se puede observar en los cuentos "Hormigas" y "El chupamirto" de Los mástiles, de Jorge López Páez, o en el relato "La tía Carlota", de Tiene la noche un árbol, de Guadalupe Dueñas, por mencionar algunos casos; incluso, este rasgo es algo que señalan (luego de un test psicológico) de la personalidad de Carlitos, protagonista de Las batallas en el desierto, de José Emilio Pacheco.
} 
sabré nunca, si para mis hermanos. Yo jamás he podido confesarles mis pánicos ni contarles nada de lo que me ocurre por las noches; temo que se burlen de mí y me pongan algún apodo ridiculo y bumillante" (2002: 47-48).

Al igual que el protagonista de "Alta cocina", Marcos, su par en "El jardín de las tumbas", todavía siente los estragos de aquellos momentos del pasado: "A los cuarenta años tampoco podía vencer el miedo a la oscuridad; se sentía perdido en la tiniebla” (2002: 48). Incluso, tras años de convivencia aparentemente cercana con sus hermanos, en el presente no los conoce, reflexiones de las que nos entera la voz narrativa en redondas: "Aún no sabía gran cosa de sus hermanos: se querían bien respetándose en todo, se buscaban con cierta frecuencia y charlaban a gusto, pero siempre había existido algo como una barrera interior que él no lograba franquear. Tal vez vivía muy encerrado en su propio mundo y no le interesaba moverse en el de ellos" (2002: 50).

En el marco de las reformulaciones que ha tenido el tema de la infancia en la literatura mexicana a partir de los ańos cincuenta, son abundantes las anécdotas de tristeza, soledad e inseguridades que relatan los adultos que se embarcan en la narración de los supuestos "años maravillosos"; parece que en esos tiempos residen los orígenes de ciertos malestares que son vigentes en la madurez. Desde el presente de enunciación, ya sea un narrador extradiegético o uno homodiegético, se llega a reconocer que la infancia fue "la soledad a cuestas siempre" (2002: 50).

Sobre este cuento, Maricruz Castro Ricalde ha dicho que, además del presente del adulto y del pasado registrado en el diario, hay un tercer tiempo que "es el real, surge en la parte final del cuento y está indicado por el único espacio en blanco, topográficamente hablando, en el cuento. Solo hasta este momento, el lector se entera de que los dos relatos anteriores son el sueńo de Marcos que sigue siendo un niño. Esta estrategia transforma los tiempos anteriores 
en unos de naturaleza condicional, hipotética" (2009: 124). En esta lógica, el adulto es una proyección que denota una tremenda incertidumbre: "La angustia de Marcos niño ante su aislamiento es tal que sueña que en el futuro seguirá solo, sin encontrar el amor ideal, remedio para las pesadillas que asuelan sus noches" (2009: 132). Con esta interpretación, damos por hecho que un personaje infantil tiene tanto conocimiento del mundo adulto que hasta sueña con él; en definitiva, nos ofrece otra variante para una lectura diferente sobre el mismo texto. Lo que tristemente no cambia es el aislamiento que embarga al niño, se trate de un sueño o no lo que ocurre con su yo adulto.

\section{Breves conclusiones}

La noción de infancia y algunos personajes niños son constantes interesantes en la obra de Amparo Dávila. La primera aparece en varios textos y la autora no se limita a emplear los lugares comunes que sobre ella existen desde hace siglos, sino que los maneja de acuerdo a las necesidades de sus historias, así se trate de una breve mención o de configurar un texto a partir de tales elementos, como en "El huésped". En cuanto a presentar la infancia como un periodo no tan grato, los protagonistas de "Alta cocina" y "El jardín de las tumbas" han sido menores aquejados por miedos y frustraciones que se proyectan hacia el futuro; si consideramos que en condiciones favorables "[d]esde el yo se afianza una idea de identidad en la cual la infancia desempeña un papel primordial: es una postulación de la infancia por un sujeto anhelante de un pasado personal sobre el que fundar su conciencia de sí (Cabo, 2001: 51), constatamos, en la obra de Dávila, que los adultos no logran escapar de las tempestades de la infancia, las cuales hemos visto cómo afectan a niñas/mujeres sobreprotegidas o a sujetos pusilánimes que no logran despojarse de las inseguridades de la niñez. Los 
personajes de Amparo Dávila no son los únicos: al igual que otros protagonistas de la literatura mexicana, lejos están de presumir que la infancia sea una época dorada.

\section{Bibliografía}

Cabo Aseguinolaza, Fernando, 2001, Infancia y modernidad literaria, Biblioteca Nueva, Colección Interdisciplinar de Estudios Culturales 1, Madrid.

Castro Ricalde, Maricruz, 2009, "De solterías, soledades y aislamientos", en Amparo Dávila: Bordar en el abismo, Regina Cardoso Nelky y Laura Cázares (eds.), Instituto Tecnológico de Estudios Superiores de Monterrey / Universidad Autónoma Metropolitana, Colección Desbordar el canon, Toluca, pp. 121-136.

Dávila, Amparo, 2002, Música concreta [1964], Letras Mexicanas 79, Fondo de Cultura Económica, México.

, 2003, Tiempo destrozado [1959], Letras Mexicanas 46, Fondo de Cultura Económica, México.

, 2009, Árboles petrificados [1977], en Cuentos reunidos, Fondo de Cultura Económica, México.

Muñoz Figueroa, Jorge, 2008, "Los narradores de los cincuenta en busca de su tiempo perdido", Decires, vol. 11, núm. 12-13, México, pp. 113-131. Disponible en: http://www.revistadecires. cepe.unam.mx/articulos/art12-8.pdf

, 2018, "Más allá del cuento fantástico. El tema de la infancia en la obra de Guadalupe Dueñas y Amparo Dávila", Pirandante, núm. 1, Tlaxcala, enero-junio, pp. 9-29. Disponible en: https://pirandante.filosofia.uatx.mx/index.php/mas-alla-delcuento-fantastico-el-tema-de-la-infancia-en-la-obra-de-guadalupe-duenas-y-amparo-davila/ 
2018a, "La infancia en el cuento mexicano del siglo XX”, Encuentros2050, núm. 20, año 2, México, agosto, pp. 15-17. Disponible en: https://encuentros2050.wordpress. com/2018/09/11/agosto-2018/

Pavón, Alfredo, 2000, "Prólogo", en Cuento mexicano moderno, Universidad Nacional Autónoma de México / Universidad Veracruzana / Aldus, México, pp. IX-XXII.

Pitol, Maricarmen, 1996, "Amparo Dávila, el angustioso retorno al mundo infantil", en Escribir la infancia. Narradoras mexicanas contemporáneas, Nora Pasternac, Ana Rosa Domenella y Luzelena Gutiérrez de Velasco (coords.), El Colegio de México, Programa Interdisciplinario de Estudios de la Mujer, México, pp. 285-297.

Romano Hurtado, Berenice, 2009, "Lo indecible del dolor: la expresión del terror en Tiempo destrozado", en Amparo Dávila: Bordar en el abismo, Regina Cardoso Nelky y Laura Cázares (eds.), Instituto Tecnológico de Estudios Superiores de Monterrey / Universidad Autónoma Metropolitana, Colección Desbordar el canon, Toluca, pp. 107-118. 